\title{
Human Resources Responsibility on Job Satisfaction
}

\author{
Dr. Mallikarjuna NL
}

\begin{abstract}
Job satisfaction means sense of inner fulfillment and pride achieved when performing a particular job. Job satisfaction occurs when an employee joyously feels that he has accomplished something which is having importance and value worthy of recognition. Job satisfaction plays very vital role in terms of retention of employees in an organization and retention of talented employees is a big challenge in today's competitive and dynamic business environment. Hence, it is important to understand why employees get dissatisfied? Employees have been forced to take on larger workloads; employees have experienced significantly added stress without receiving compensatory rewards. HR regularly has to chart out the plans and providing ways to reduce dissatisfaction among employees. This paper attempts to focus on the reasons of employee's dissatisfaction \& the ways to improve employee's job satisfaction.
\end{abstract}

Keywords: Job enrichment, Job Satisfaction, Retention, Reward systems, Work life Balance.

\section{Introduction}

Job satisfaction is one's feelings regarding the nature of their work. Job satisfaction can be influenced by a variety of factors, example, the quality of one's relationship with their supervisor, the quality of the physical environment in which they work, degree of fulfillment in their work, etc .Job satisfaction describes how satisfied an individual is with his or her job. Job satisfaction is not the same as motivation but it is related to motivation also .Job design aims to enhance job satisfaction and performance; methods include job rotation, job enlargement and job enrichment. Other influences on satisfaction include the management style and culture, employee involvement, empowerment and autonomous work groups. Job satisfaction is a very important attribute which is frequently measured by organizations. Various factors influence job satisfaction and our understanding of the importance of these factors in part from Frederick Hertzberg called elements such as remuneration, working relationships, status and job security "Hygiene factors" because they concern the framework in which somebody works.

Hygiene factors do not in themselves promote job satisfaction, but serve primarily to prevent job contribute to job satisfaction and include achievement, recognition, the work itself, responsibility, advancement, and growth. An absence of job satisfaction can lead to poor motivation, stress, absenteeism, and high labor turnover.

\section{Why Employee Satisfaction Is Important?}

Retaining and finding the best talent is becoming harder and harder. Positively influencing staff is one way to develop an environment and culture where people want to do their best and want to stay. Success comes through people. When companies are effective in satisfying their employees, employees stay longer, make a deeper commitment to the business, suggest ways to improve the company's products and services, and work harder to satisfy the customer. In almost every survey - factors that motivate employees in the workplace, job satisfaction is at or near the top of the list, far surpassing pay and benefits. Creating a work environment that encourages speedy response to customers' needs and attentive follow-through is the key to leveraging the power of the service-profit chain. This is only possible when people are empowered to make decisions and are motivated to solve problems. Encourage employees to go ahead of the literal boundaries of their jobs to make suggestions for improvement and an organization will gain not just a part, but the full potential of their contributions to the business.

\section{WHY INDIVIDUALS LOSE JOB SATISFACTION?}

$>$ Backbiting co-workers

$>$ Conflict with your supervisor

$>$ Not being appropriately paid for what you do.

$>$ Not having the necessary equipment or resources to succeed

$>$ Lack of opportunities for promotion.

$>$ Having little or no say in decisions that affect an individual.

$>$ Fear of losing the job.

$>$ Work that an individual find boring or overly routine

$>$

One must take some time to think about what motivates and inspires him or her. Individual may even want to work with a career counselor to complete a formal assessment of his or her interests, skills and passions. 
Human Resources Responsibility On Job Satisfaction

The Link Between Work Approach And Job Satisfaction

Work is often approached from three perspectives. Usually all three perspectives are important for job satisfaction, but one is often the priority:

Approach As A Job:

If an individual approach works as a job, his or her focus will be primarily on the financial rewards. In fact, the nature of the work may hold little interest for them . What's important is the money. If a job with more pay comes their way, they will likely move on.

Approach As A Career:

If an individual approach work as a career, means he or she is interested in advancement. They want to go up the career hierarchy as far as possible or be among the most highly regarded professionals in their field. They are motivated by the status, prestige and power that come with the job.

Approach As A Calling:

If an individual approach his or her job as a calling, they focus on the work itself. They work less for the financial gain or career advancement than for the fulfillment the work brings. One must recognize his or her approach to work? One approach isn't necessarily better than the others. But it's helpful to reflect on why an individual work if he or she is unsatisfied with his or her job and are ready to move on.

\section{Strategies To Improve Job Satisfaction}

Various strategies to improve job satisfaction are as follows:

(1) SET NEW CHALLENGES FOR YOUR EMPLOYEES: If you reveal that an employee stuck in a job because of lack of education or a downturn in the economy, it doesn't mean his or her work has become drudgery. With a little imagination, he can create new challenges and make the best of the job he have. Here are some ideas for helping him/her in this situation:

I. IMPROVE JOB SKILLS: Let employee imagining himself/herself in dream job, employee might envision himself as an excellent project manager a confident communicator and a highly organized person.

II. LET EMPLOYEE TO DEVELOP HIS/HER OWN PROJECT: Employee can take on a project that can motivate him and give him a sense of control. Start small, such as organizing a work-related celebration, before moving on to larger goals.

III. LET EMPLOYEE TO MENTOR A CO-WORKER: Once an employee mastered a job, he may find it becoming routine. Helping a new co-worker or an intern advance his or her skills can restore the challenge and the satisfaction he or she desire.

(2) MATCH EMPLOYEE ABILITIES WITH RESPONSIBILITIES: If employ

his responsibilities, job becomes boring. Following are some suggestions:

BREAK UP THE MONOTONY: Take advantage of the work breaks. Read, listen to music and go for a walk. Even write a mail.

CROSS-TRAINING: If the work consist of repetitive tasks, such as entering data or working on an assembly line talk with the boss about training for a different task to fight boredom.

VOLUNTEER FOR SOMETHING DIFFERENT: If an employee hears that his company is launching a new project, he can volunteer for the work team.

GROWTH OPPORTUNITIES: Providing employees better growth opportunities is very important as far as understanding their abilities is concerned.

(3) KEEP YOUR EMPLOYEES ALWAYS POSITIVE: Inculcate positive thinking in your employees to reframe their thought process about their job. Changing your attitude about work won't necessarily happen overnight or increase the job satisfaction overnight. Following are some techniques:

STOP NEGATIVE THOUGHTS: Pay attention to the messages an employee give himself. When he catches himself thinking his job is terrible, stop the thought in its tracks.

PUT THINGS IN PERSPECTIVE: Remember everyone encounters good days and bad days on the job.

LOOK FOR THE SILVER LINING: "Reframing" can help an employee find the good in a bad situation. For example, employee receives a less than perfect performance appraisal and his boss warns him to improve or move to another job. Instead of taking it personally or looking for another job right away, look for the silver lining. Depending on where he work, the silver lining may be attending continuing education classes or working closely with a performance coach and having the satisfaction of showing the boss that you're capable of change.

LEARN FROM YOUR MISTAKES: Failure is one of the greatest learning tools, but many people let failure defeat them. When an employee makes a mistake at work, let him learn from it and ensure that he or she might not try that again.

\section{(4) ENERGIZE EMPLOYEES: THE POWER OF RECOGNITION}

There is more than enough research to show people are more motivated by recognition than money. Especially the young blood (generation) with lower experience as they are already very energetic and dynamic. Cultivating and motivating them through "Recognition" enhance their job satisfaction reducing attrition rate. Recognition can be provided by the following means: 


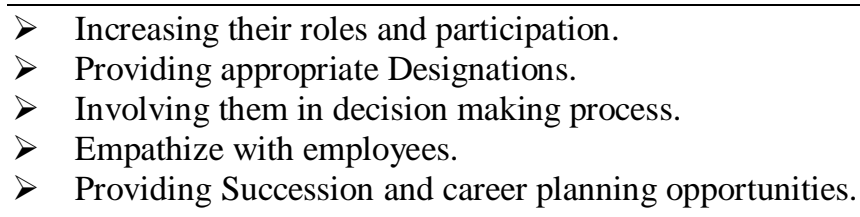

(5) INSPIRE EMPLOYEES: REWARD SYSTEMS

The greatest management principle is that the things that get rewarded get done fast.

I. EMPOWERING THE PEOPLE AROUND US: The three general rules for a boss empowering the people around are appreciation, approval, and attention. Boss has to voice his thanks and gratitude to others on every occasion. He must praise them for every accomplishment \& pay close attention to them when they talk and want to interact with their boss. These three behaviors alone will make a boss a master of human interaction and will greatly empower the people around him.

II. TO KNOW HOW SATISFIED THE EMPLOYEES ARE: How satisfied are our employees with their jobs and the company? One should be asking this question quite often. For the reason, that a worker who is not satisfied with his job would not only be looking for a new job, he or she will also be uninterested in performing at their full potential and they will transfer this negativity into their fellow workers and one will be left with a workforce where majority of the workers is discontent with their jobs. Job satisfaction is a product of many elements, some of the important ones are remuneration package, workforce environment, management style and the nature of the duties assigned.

(6) PROPER MANAGEMENT STYLE The relationship between the manager and subordinates is a very critical one, if the managers or supervisors are disrespectful or unconcerned about their subordinate's emotions the job satisfaction level is always going to be low, no matter what the other instrumental factors are. Nobody likes discriminatory treatment, insulting remarks or overly authoritative behavior. Employees should feel at ease in the workplace, therefore the supervision should not unnecessarily break the comfort level. (7) CONDUCIVE WORKFORCE ENVIRONMENT AND HEALTH ISSUES

Bad working conditions include bad lighting, insufficient ventilation, hot temperatures or any other kind of health $\mathrm{h}$

priority basis without waiting for someone coming up with complains. In addition to the physical safety, working environment should also be able to provide mental peace. Issues like overly aggressive supervisors, passionate co-workers or impractical work targets can spoil the peace of mind.

(8) A GOOD SALARY PACKAGE CAN CANCEL OUT VARIOUS MINOR ISSUES Probably the most influential factor in job satisfaction is the remuneration one gets for his job, a reasonable pay will compensate for many hitches, for example work overload, overtime or even a stressful job. Job satisfaction is directly related to remuneration packages and dissatisfaction mostly come up when a worker feels that he is not being appropriately compensated for the work he is doing for the company.

(9) EXPLORING ECONOMIC CONDITION OF EMPLOYEES: HR person should explore the economic conditions and priorities of every employee through proper communication channel so that the increments and other financial rewards should meet the employees expectations. Though tackling this issue is quite subjective in nature but even then employees having severe financial needs will be served on priority basis as compared to other employees, keeping other employees in confidence. This boosts the employee overall job satisfaction and became more productive for an organization.

(10) JOB SATISFACTION THROUGH JOB ENRICHMENT

One of the key factors in good job design is job enrichment, most notably promoted by psychologist Frederick Hertzberg .He focused on the practice of enhancing individual jobs to make the responsibilities more rewarding and inspiring for the people who do them. Job enrichment expands the task set that someone performs. More stimulating and interesting work is provided that adds variety and challenge to an employee's daily routine. This increases the depth of the job and allows people to have more control over their work. Job enrichment addresses these factors by enhancing the job's core dimensions and increasing people's sense of fulfillment.

\section{(11) DESIGNING JOBS THAT MOTIVATE}

There are five factors of job design that typically contribute to people's enjoyment of a job which leads to job satisfaction:

SKILL VARIETY: Increasing the number of skills that individuals use while performing work.

TASK IDENTITY: Enabling people to perform a job from start to finish.

TASK SIGNIFICANCE: Providing work that has a direct impact on the organization or its stakeholders.

AUTONOMY: Increasing the degree of decision making, and the freedom to choose how and when work is done.

FEEDBACK: Increasing the amount of recognition for doing a job well, and communicate the results of people's work. 
(12) WORK LIFE BALANCE This is an emerging issue all across organizations as it is very essential aspect for every employee, especially females to balance their personal and professional lives. Research indicated that one of the important factors is tight, hectic and rigorous work schedules which adversely affect the employees satisfaction level, lead to high attrition rate in organizations. Facilities like Flexible working hours and work from home may results in better work life balance thus enhancing the overall job satisfaction.

\section{More Job Satisfaction Means Less Stress}

Key employee retention is critical to the long term health and success of the business. Managers readily agree that retaining the best employees ensures customer satisfaction, product sales, satisfied coworkers and reporting staff, effective succession planning and deeply imbedded organizational knowledge and learning. If managers can name these facts so well, why do they behave in ways that so frequently encourage great employees to quit their jobs?

Various estimates suggest that losing a middle manager costs an organization up to 100 percent of his salary. The loss of a senior executive is even more costly.

workplace. A motivated employee wants to contribute to work areas outside of his specific job description. As an example, in a small company, a manager pursued a new marketing plan and logo with the help of external consultants. An internal sales representative with seven years of ad agency and logo development experience repeatedly offered to help. His offer was ignored and he cited this as one reason why he quit his job. In fact, the recognition that the company didn't want to take advantage of his knowledge.

\section{Conclusion}

Some of the organizations, in spite of the focus on the importance of human resources management in an organization, still pay less attention to the importance of job satisfaction. Due to lack of job satisfaction, most organizations either perform badly or lose skilled employees to other organizations with strong human resource policies. The organizations need to take note that A happy employee is a happy customer". Job satisfaction is a

them. It is seen as the emotional response to a job situation. Job satisfaction as seen in the manner in which the employees react and respond to the job situation. Job satisfaction being determined by how outcomes meet or

ways for improving job satisfaction which ultimately lead to the vibrant growth of an organization by keeping the experienced, trained, talented \& skilled employees with a company to achieve competitive environment in

\section{References}

[1.] A g a r w a 1 a, T., 2008, The relationship between workplace training and organizational commitment in manufacturing firms: Evidence from India. Paper presented at the 7th International Conference on Ethics and Quality of Work-life for Sustainable Development, Bangkok, Thailand,

[2.] . Asia Pacific Journal of Human Resources, 2005, Vol.43, No.3, pp.332-360,

[3.] B u d h w a r, P. S., D e b r a h, Y. A. (Eds.) 2001 Human resource management in developing countries. London: Routledge,.

[4.] Chhabra T. N. (2009), "Job satisfaction, Alienation and Stress ", Human Resource Management, Fifth edition (2009), ISBN 8177000268 , Page No $690-711$

[5.] Chowdhary, Abhishek Roy (2011), "Why Employees get Demotivated? " , HRM Review - An IUP Publication ,Vol XI, No. 10, Oct-Dec 2011, Pages 46-40.

[6.] D a vi d s o n, W.L.1979 How to develop and conduct successful employee attitude surveys. Horsham, PA: The Dartnell Corporation., 1979.

[7.] D e 1 a n e y, J. T., H u s e 1 i d, M. A., 1996 The impact of human resource management practices on perceptions of organizational performance. The Academy of Management Journal, Vol.3, No.4, pp. 949-969, 1996.

[8.] E d g a r , F., G e a r e , A., 2005, HRM practice and employee attitudes: Different measure s- different results. Personnel Review, Vol.34, No.5, pp. 534-549,

[9.] G a r c i a , M., 2005, Training and business performance: The Spanish case. International Journal of Human Resource Management, Vol.16, pp.1691-1710,

[10.] G o u l d-Wi 11 i a m s , J., 2003, The Importance of HR practices and work Place trust in achieving superior performance: a study of public-sector organizations. International Journal of Human Resource Management, Vol.14, No.1, pp. 28-54,.

[11.] H u n t e r, E.J., S c h m i d t , L.F.,1982, Ability tests: economic benefits versus the issue of fairness, Industrial Relations, Vol.21, No.3, pp.293-309,

[12.] Lal Madhurima \& Zaidi S. Q. ,(2008), "Job Evaluation and Job satisfaction" , Human Resource Management , First edition (2008), ISBN 9788174466853 , Excel Books ,New Delhi, Page No. 149 - 191.

[13.] Rane, D.B. (2011), " Employee Job Satisfaction: An Essence of Organization HRM Review - An IUP Publication, Vol XI, No. 7, July 2011, Pages 10-16. 